\title{
Emerging combination therapies for the management of multiple myeloma: the role of elotuzumab
}

This article was published in the following Dove Press journal:

Cancer Management and Research

12 July 2017

Number of times this article has been viewed

\author{
Wei-Chih Chen' \\ Abraham S Kanate ${ }^{2,3}$ \\ Michael Craig ${ }^{2,3}$ \\ William P Petros 1,3 \\ Lori A Hazlehurst ${ }^{1-3}$ \\ 'Department of Pharmaceutical \\ Sciences, School of Pharmacy, ${ }^{2}$ Osborn \\ Hematopoietic Malignancy and \\ Transplantation Program, West Virginia \\ University, ${ }^{3}$ West Virginia University \\ Cancer Institute, Morgantown, WV, \\ USA
}

\begin{abstract}
Treatment options for patients with multiple myeloma (MM) have increased during the past decade. Despite the significant advances, challenges remain on which combination strategies will provide the optimal response for any given patient. Defining optimal combination strategies and corresponding companion diagnostics, that will guide clinical decisions are required to target relapsed or refractory multiple myeloma (RRMM) in order to improve disease progression, survival and quality of life for patients with MM. Elotuzumab is a humanized monoclonal antibody that targets signaling lymphocytic activation molecule F7 (SLAMF7), approved by the US Food and Drug Administration (FDA) in 2015 and the European Medicines Agency in 2016 for the treatment of MM. SLAMF7 is expressed in normal and malignant plasma cells and has lower expression on natural killer (NK) cells. Experimental evidence indicates that elotuzumab exhibits anti-myeloma activity through 1) antibody-dependent cell-mediated cytotoxicity, 2) enhancing NK cells cytotoxicity and 3) interfering with adhesion of MM cells to bone marrow stem cells (BMSCs). Although elotuzumab has no single agent activity in patients with RRMM who have received one to three prior therapies, the combination of elotuzumab with anti-myeloma agents, such as immunomodulatory drugs-lenalidomide, or proteasome inhibitors (PIs)-bortezomib, remarkably improved the overall response rates and progressionfree survival in MM patients with only minimal incremental toxicity. In brief, the clinical data for elotuzumab indicate that targeting SLAMF7 in combination with the use of conventional therapies is feasible and effective with a tolerable safety profile for the treatment of RRMM.
\end{abstract}

Keywords: elotuzumab, SLAMF7, relapsed/refractory multiple myeloma (RRMM)

\section{Introduction}

Multiple myeloma (MM) is the second most common hematologic malignancy, featuring abnormal proliferation of plasma cells in the bone marrow. Although the etiology of MM remains unknown, patients with MM often suffer end-organ damage, including hypercalcemia, renal disease, anemia and bone lesions, also known as the CRAB characteristics. ${ }^{1,2}$ Factors associated with a poorer prognosis include: 1) age, who are $>65$ years of age; 2 ) gender: men who are at slightly greater risk than women; 3 ) race: African Americans who are more susceptible than white Americans; 4) those with a family history of MM; 5) obesity/overweight and 6) those with a history of other plasma cell diseases. ${ }^{3,4}$

Patients with MM who are $<65$ years of age, treated with high-dose therapy and autologous stem cell transplantation (ASCT) have improved progression-free survival (PFS) and overall survival (OS) compared with patients who do not receive ASCT. Many patients with myeloma are elderly or have comorbid conditions which
Correspondence: Lori A Hazlehurst Department of Pharmaceutical Sciences, School of Pharmacy, West Virginia University, One Medical Drive, Morgantown, WV 26506, USA Email lahazlehurst@hsc.wvu.edu 
may not allow for ASCT. ${ }^{4} \mathrm{New}$ approaches for MM treatment, especially immunomodulatory drugs (IMiDs) and proteasome inhibitors (PIs), appear to improve response and extend survival. ${ }^{5}$ Although the mortality rates of MM have declined in the past decade, the overall incidence rate of MM continues to increase, and $<50 \%$ of patients are alive for 5 years after their initial diagnosis. ${ }^{6}$ Current challenges in the clinical management of MM include resistance to PIs and IMiDs and tolerability. The estimated median OS of the patients with MM who are refractory to PIs and IMiDs is $\sim 9$ months and the median event-free survival is $<5$ months. ${ }^{7,8}$ Monoclonal antibodies (mAbs) designed to target highly expressed antigens on cells have emerged as a potential strategy for targeted cancer therapies. More than $10 \mathrm{mAbs}$ were approved by the US Food and Drug Administration (FDA) for various solid tumor and hematological malignancies since 1997. Understanding lineage or tumor restricted expression of surface receptors could lead to increased specificity of antibody strategies for killing tumor cells. Indeed, compared with standard chemotherapy, this antibody-targeted approach has shown efficacy with less severe toxicities. ${ }^{9}$

Recently, a number of novel agents with different mechanisms of action have been developed based on an increased knowledge of the pathophysiology of MM, including new generations of PIs, IMiDs, mAB, vaccines, other immunotherapies, histone deacetylase inhibitors, alkylating agents, kinase inhibitors, and the heat shock protein inhibitors. ${ }^{10-15}$ Therapeutic mABs may directly induce growth inhibition by interfering with receptor-ligand interactions, induce antibody-dependent cellular cytotoxicity (ADCC) stimulate apoptosis signaling cascades, or act as a carrier of chemotherapy (antibody drug conjugate) or radioisotopes.

Elotuzumab is a humanized $\mathrm{mAB}$ indicated in MM patients after failure of one to three prior therapies. Eotuzumab was granted "Breakthrough Therapy" designation for MM by the FDA in May 2014 and was approved by FDA in November 2015 and by European Medicines Agency in May 2016 for patients with RRMM. Elotuzumab was labeled for use with combination chemotherapy to treat MM.

\section{Mechanism of action of elotuzumab}

The mechanisms of action of elotuzumab include 1) enhancing natural killer (NK) cells' cytotoxicity through the Fab portion of elotuzumab binding to signaling lymphocytic activation molecule F7 (SLAMF7) receptor on NK cells; 2) elotuzumab binds to SLAMF7 receptor on MM cells and CD16 receptor on NK cells that activate NK cells to kill MM cells by mediating ADCC and 3) elotuzumab inhibits MM cells to interact with bone marrow stromal cells (BMSCs) (Figure 1). Blockade of the CD16 (Fc receptor) on NK cells or depletion of NK cells from peripheral blood mononuclear cells (PBMCs) significantly inhibits elotuzumab-mediated ADCC activity. There is no effect on elotuzumab-mediated ADCC by depleting $\mathrm{T}$ cells, B cells or monocytes from PBMCs, suggesting ADCC induction by elotuzumab is dependent on NK cells. ${ }^{16}$

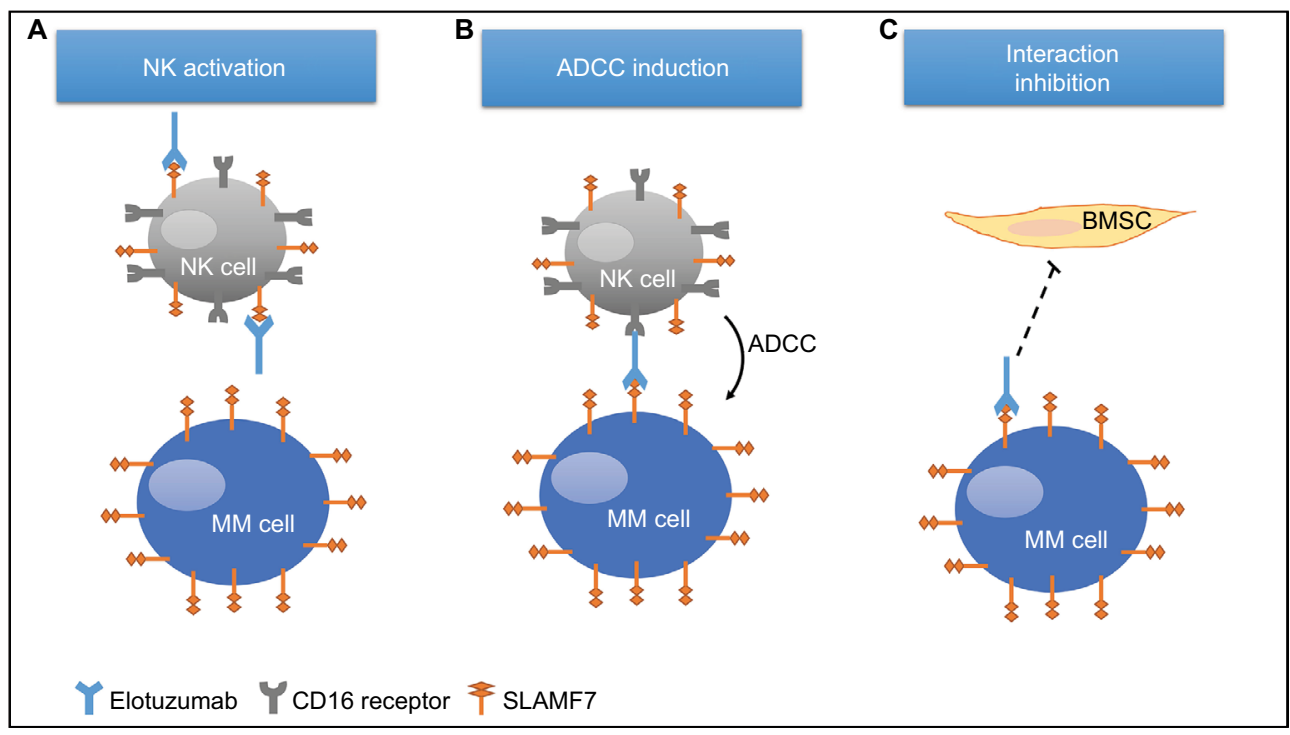

Figure I Mechanism of action of elotuzumab.

Notes: (A) Elotuzumab activates NK cells directly through the binding of SLAMF7 expressed on NK cells; (B) elotuzumab binds to SLAMF7 receptor on MM cells and CDI6 receptor on NK cells to mediate the killing of MM cells through ADCC; and (C) elotuzumab inhibits MM cells to interact with BMSCs by binding SLAMF7 expressed on MM cells.

Abbreviations: ADCC, antibody-dependent cell-mediated cytotoxicity; BMSCs, bone marrow stem cells; MM, multiple myeloma; NK, natural killer; SLAMF7, signaling lymphocytic activation molecule F7. 
In coculture experiments, elotuzumab treatment or reducing the expression of SLAMF7 interfered with MM cell adhesion to BMSCs, suggesting elotuzumab may reverse cell adhesion-mediated drug resistance associated with conventional therapies. ${ }^{17-19}$

\section{Preclinical experiences with elotuzumab}

HuLuc63, later named elotuzumab, is a humanized anticell surface 1 (CS1) mAb, which recognizes the extracellular domain of CS1 (also known as SLAMF7). HuLuc63 significantly abrogated the growth of the human myeloma cell line OPM2 using a murine xenograft model by ADCC induction. The antitumor activity is related to the presence of functional NK cells. ${ }^{16}$

CS1 belongs to the SLAM family and was found to be highly expressed in malignant and normal plasma cells. CS1 is also expressed on the CS of NK cells, NK-like T cells, CD8-positive $\mathrm{T}$ cells, mature dendritic cells and activated B cells but was not found on other normal tissues. ${ }^{16,20,21}$ Expression of CS1 is frequent in MM cell lines (mRNA 45 of 45; protein 14 of 15 are expressed). CS1 was detected in the majority of MM specimens (98 of 101), but not in healthy donors and is one of the critical regulators of immune response contributing to survival regulation in MM. Due to restricted expression of SLAMF7; elotuzumab demonstrates minimal adverse effects (AEs) on normal tissue, suggesting a high therapeutic index in MM. ${ }^{21}$

Lenalidomide (Celgene Corporation; Summit, NJ, USA) is a highly effective IMiD approved for MM patients. ${ }^{22-24}$ Evidence has shown that antitumor activity of lenalidomide is through multiple mechanisms including enhancement of T-cell and NK-cell activations, repression of angiogenesis, altering cytokine production and direct inhibition of tumor cell growth. ${ }^{25-27}$

Lymphocyte function-associated antigen 1, also known as LFA-1 (CD11a/CD18) is an adhesion molecule. LFA-1 is a requirement for the adhesion of NK cells to target cells through binding to intercellular adhesion molecule (ICAM-1). The interaction of LFA-1 and ICAM-1 is associated with multidrug resistance induction in vitro. Using antiCD18 mAb to interrupt LFA-1/ICAM-1 interaction decreased elotuzumab activity as a single agent or in combination with lenalidomide-using both cell MM cell death and NK activity as endpoint measurements. ${ }^{28,29}$ Together, these data suggest that elotuzumab-induced cell death and NK activity is partially dependent on LFA-1 function on NK cells.

The combination of elotuzumab with lenalidomide enhanced antiproliferative effect more than elotuzumab or lenalidomide monotherapy using either in vitro or in vivo models of MM. ${ }^{30}$ This enhanced anti-myeloma activity correlated with NK activation, increased cytokine secretion and LFA-1/ICAM-1 interaction. ${ }^{31,32}$

Bortezomib (Takeda Pharmaceutical Company, Osaka, Japan) is the first PI approved for MM patients. ${ }^{31}$ Evidence indicated that bortezomib sensitized myeloma cell lines and primary myeloma cells to elotuzumab-mediated ADCC. Moreover, the combination of elotuzumab and bortezomib significantly increased anti-myeloma activity compared with single agent in the OPM2 MM xenograft model. ${ }^{33}$

In addition to direct effects on the myeloma cell, bortezomib was shown to downregulate major histocompatibility complex class I expression on the MM cell lines and patient MM cells leading to enhanced sensitivity of MM cells to NK cell-mediated lysis. ${ }^{32}$ The increase in NK-mediated lysis may contribute to the favorable anti-myeloma response when elotuzumab is combined with bortezomib. CS1 (SLAMF7) RNA and protein expressions of patients with MM ( $n=103)$ resulted in no significant change on the CS after bortezomib administration, compared with the untreated group indicating that changes in CS expression of CS1 do not correlate with increased activity of the combination treatment regimen.

Taken together, the preclinical data suggest that elotuzumab is an attractive agent to combine with conventional therapies such as lenalidomide and bortezomib.

\section{Clinical experiences with elotuzumab Monotherapy}

The first-in-human study of elotuzumab was designed as a monotherapy to evaluate the safety, tolerability and pharmacokinetic and pharmacodynamic properties of elotuzumab in patients with RRMM. Thirty-five patients were enrolled and received escalating doses of elotuzumab from 0.5 to $20 \mathrm{mg} / \mathrm{kg}$ by intravenous (IV) infusion on an every 14 days scheme. According to European Group for Bone and Marrow Transplantation myeloma response criteria, $26.5 \%(n=9)$ patients had stable disease, also the best-observed response. However, no objective responses were observed in this trial. Collectively the preclinical and early clinical data suggested that elotuzumab alone, albeit safe, was not sufficient to produce tumor response in RRMM but maybe a candidate for combination strategy. ${ }^{34}$

\section{Combination therapy}

Preclinical studies demonstrated that elotuzumab in combination with other agents, including lenalidomide and bortezomib showed increased antitumor activity compared 
to single agent treatment. ${ }^{21,33}$ To evaluate the maximum tolerated dose (MTD), efficacy, safety of elotuzumab in combination with lenalidomide and dexamethasone. A Phase I study of elotuzumab at a dose of 5,10 and $20 \mathrm{mg} / \mathrm{kg}$ with lenalidomide and low-dose dexamethasone in patients with RRMM yielded an overall response rates (ORRs) of 82\% (23 of 28); the median time to progression (TTP) had not been reached after a median of 16.4 months of follow-up in the 20 $\mathrm{mg} / \mathrm{kg}$ cohort. ${ }^{35}$ Another Phase I/II, multicenter, open-label multiple-dose, dose escalation study investigated MTD safety and efficacy of elotuzumab in combination with bortezomib in patients with RRMM (ClinicalTrials.gov Identifier: NCT00726869). Twenty-eight patients with a median of two prior therapies were enrolled and received escalating doses of elotuzumab from 2.5 to $20 \mathrm{mg} / \mathrm{kg}$ IV and bortezomib (1.3 $\left.\mathrm{mg} / \mathrm{m}^{2} \mathrm{IV}\right)$. The ORR was $48 \%(\mathrm{n}=13)$ and $63 \%(\mathrm{n}=17)$ of patients achieved a minor response or better. The median TTP was 9.46 months. Two of three $(66.7 \%)$ patients who were bortezomib-refractory previously showed objective response with the addition of elotuzumab. Seventy percent (7 of 10) of patients with high-risk cytogenetics showed an objective response. MTD was not observed at the maximum planned dose of $20 \mathrm{mg} / \mathrm{kg}$ of elotuzumab. ${ }^{36}$

The above Phase I results were encouraging- and elotuzumab-based combination therapy proceeded into Phase II trials. In a Phase II study, 73 patients with RRMM were enrolled (median age 63 years; range 39-82) and treated with elotuzumab $10 \mathrm{mg} / \mathrm{kg}, \mathrm{n}=36$ or $20 \mathrm{mg} / \mathrm{kg}, \mathrm{n}=27 \mathrm{plus}$ lenalidomide and low-dose dexamethasone. The ORR was $84 \%$ (10 mg/kg group was $92 \%$ and $20 \mathrm{mg} / \mathrm{kg}$ group was $76 \%$ ); the median PFS was 29 months $(10 \mathrm{mg} / \mathrm{kg}$ group was 32 months and $20 \mathrm{mg} / \mathrm{kg}$ group was 25 months). ${ }^{37}$ Owing to the safety and excellent efficacy at a lower dose, $10 \mathrm{mg} / \mathrm{kg}$ of elotuzumab was selected as the dosage for the Phase III trials, ELOQUENT-1 and ELOQUENT-2. ${ }^{38}$

The ongoing Phase III ELOQUENT-1 trial is a randomized, open-label study comparing lenalidomide/low-dose dexamethasone alone or in combination with elotuzumab in newly diagnosed MM. The primary end point is PFS and secondary end points include ORR and OS. This trial started in May 2011, and the estimated enrollment is 750 patients and the estimated study completion date will be July 2019 (ClinicalTrials.gov Identifier: NCT01335399).

The ongoing Phase III ELOQUENT-2 trial is a randomized, open-label study to assess whether the addition of elotuzumab to lenalidomide/low-dose dexamethasone will increase the PFS in patients with RRMM. Patients with RRMM were randomized to the control arm (lenalidomide/ dexamethasone alone) and the elotuzumab arm (elotuzumablenalidomide/dexamethassone) (ClinicalTrials.gov Identifier: NCT01239797). The interim analysis of ELOQUENT-2 published in 2015, noted a total of 646 patients, with median age of 66 years, 32\% with high-risk $17 \mathrm{p}$ deletion, $9 \%$ with $\mathrm{t}(4 ; 14)$, were randomized to the elotuzumab group $(\mathrm{n}=321)$ and the control group $(n=325)$. Patients had previously received one to three lines of therapy involving bortezomib (70\%), ASCT (55\%), melphalan (65\%), thalidomide (48\%) and lenalidomide $(6 \%){ }^{38}$

Patients received 28-day cycles of lenalidomide $25 \mathrm{mg}$ orally (days 1-21) and dexamethasone $40 \mathrm{mg}$ weekly with or without elotuzumab $10 \mathrm{mg} / \mathrm{kg}$ IV (days 1, 8, 15 and 22 in the first two cycles and days 1 and 15 from cycle 3 ). Therapy was administered until disease progression or unacceptable toxicity. The median PFS was 19.4 months in elotuzumab group and 14.9 months in control group (HR, 0.70; 95\% $\mathrm{CI}=0.57-0.85 ; p=0.004)$. The 3 -year PFS rate was $26 \%$ with elotuzumab group versus $18 \%$ with the control group (HR $0.73 ; 95 \% \mathrm{CI}=0.60-0.89 ; p=0.0014) .{ }^{39} \mathrm{ORR}$ in elotuzumab group $(79 \%)$ was significantly higher than control group $(66 \%), p=0.002 .^{38}$

ELOQUENT-3 is an open-label, Phase II trial, in which patients with RRMM are randomized to the control arm (pomalidomide/dexamethasone) or the elotuzumab arm (elotuzumab/pomalidomide/dexamethasone). It is, currently, recruiting participants and the estimated enrollment is 121 patients and the estimated study completion date is March 2019 (ClinicalTrials.gov Identifier: NCT02654132).

Mateos et al conducted a Phase II study evaluating the safety and tolerability of elotuzumab $10 \mathrm{mg} / \mathrm{kg}$ combined with thalidomide 50-200 $\mathrm{mg}$ and dexamethasone $40 \mathrm{mg}$ (with/without cyclophosphamide $50 \mathrm{mg}$ ) (ClinicalTrials. gov Identifier: NCT01632150). Forty patients were enrolled having received a median of three previous regimens, including bortezomib (98\%) and lenalidomide (73\%). Patients received 28-day cycles and continued until disease progression or unacceptable toxicity. Thalidomide was administered $50 \mathrm{mg}$ orally for the first 2 weeks, escalated to $100 \mathrm{mg}$ for the next 2 weeks and beginning with cycle $2-200 \mathrm{mg}$, once daily. Elotuzumab (10 mg/kg) was administered as an IV weekly for the first two cycles and beginning with cycle 3 . Dexamethasone was administered $40 \mathrm{mg}$ orally weekly on those weeks when elotuzumab was not administered and $28 \mathrm{mg}$ orally plus $8 \mathrm{mg} \mathrm{IV}$ on elotuzumab dosing weeks. The patients who did not have a partial response or better by the end of cycle 4 also received cyclophosphamide (50 mg). 
Those patients did not have a partial response or better by the end of cycle 4 also received cyclophosphamide, 50 $\mathrm{mg}$. The ORR was $38 \%$; the median PFS was 3.9 months; the median OS was 16.3 months and 1 -year OS rate was $63 \%$. The addition of elotuzumab to thalidomide and dexamethasone with or without cyclophosphamide resulted in minimal incremental toxicity; suggesting that elotuzumab is well tolerated in combination regimens used to treat RRMM. ${ }^{40}$

The proof-of-concept, randomized, open-label, Phase II study investigated the efficacy and safety of elotuzumab plus bortezomib/dexamethasone (EBd) and bortezomib/ dexamethasone $(\mathrm{Bd})$ in patients with RRMM. A total of 152 patients (median age 66 years) with RRMM who had received one to three prior therapies were randomized to either EBd $(n=77)$ or Bd group $(n=75)$. $E B d$ and Bd were administered until disease progression or unacceptable toxicity occurred. The results of EBd group and Bd group are as follows, the ORR: $66 \%$ versus $63 \%$; the 1 -year PFS: $39 \%$ versus $33 \%$; the 2 -year PFS: $18 \%$ versus $11 \%$ and the median PFS: 9.7 months versus 6.9 months, the OS: 51\% versus $47 \%$, respectively. EBd-treated patients homozygous for the high-affinity Fc $\gamma$ RIIIa $V$ allele (13 patients) had higher PFS than EBd-treated patients homozygous for the lowaffinity Fc $\gamma$ RIIIa F allele (24 patients), 22.3 months versus 9.8 months, respectively. Comparing the EBd group and $\mathrm{Bd}$ group, elotuzumab improved clinical benefit with limited added toxicity in patients with RRMM (ClinicalTrials.gov Identifier: NCT021478048). ${ }^{41}$ Major clinical trials of elotuzumab are listed in Table 1. As shown in Table 1, the clinical development path of elotuzumab received a breakthrough therapy designation and quickly approved under FDA's priority review process for therapeutic use in combination with lenalidomide and dexamethasone for patients with MM who have received from one to three prior therapies.

\section{Pharmacokinetics/pharmacodynamics}

Maximum elotuzumab serum concentration $\left(\mathrm{C}_{\max }\right)$ increased in a dose-proportional manner from 5 to $20 \mathrm{mg} / \mathrm{kg}$. But nonlin-

Table I Major clinical trials of elotuzumab

\begin{tabular}{|c|c|c|c|c|c|c|}
\hline NCT no. & Phase & Patient population & Regimen & Result & Status & References \\
\hline \multicolumn{7}{|l|}{ Monotherapy } \\
\hline NCT00425347 & 1 & 35 patients with RRMM & $\begin{array}{l}\text { Dose escalation E (0.5-20 } \\
\mathrm{mg} / \mathrm{kg})\end{array}$ & $\begin{array}{l}\text { CSI receptor saturation: } \\
10-20 \mathrm{mg} / \mathrm{kg} \text {; ORR: } 0 \%\end{array}$ & Completed & 34 \\
\hline \multicolumn{7}{|l|}{ Combination therapy } \\
\hline NCT00742560 & $\mathrm{lb}$ & 28 patients with RRMM & $\begin{array}{l}\text { Dose escalation } E(5-20 \mathrm{mg} \\
\mathrm{kg}) \text { plus } L \text { and } D\end{array}$ & $\begin{array}{l}\text { I ORR: } 82 \% \text {; median PFS: } \\
32.9 \text { months }\end{array}$ & Completed & 35 \\
\hline NCT00742560 & 2 & 73 patients with RRMM & $E(10 \mathrm{mg} / \mathrm{kg})$ plus $L$ and $D$ & $\begin{array}{l}\text { ORR: } 92 \% \text {; median PFS:32 } \\
\text { months }\end{array}$ & Completed & 36 \\
\hline $\begin{array}{l}\text { NCT02654I32 } \\
\text { (ELOQUENT-3) }\end{array}$ & 2 & $\begin{array}{l}\text { estimated enrolment of }|2| \\
\text { patients with RRMM }\end{array}$ & $\begin{array}{l}\mathrm{E}(\mathrm{I} 0 \text { and } 20 \mathrm{mg} / \mathrm{kg}) \text { plus } \mathrm{P} \\
\text { and } \mathrm{D}\end{array}$ & & Recruiting & \\
\hline NCT01632150 & 2 & 40 patients with RRMM & $\mathrm{E}(10 \mathrm{mg} / \mathrm{kg})$ plus $\mathrm{T}$ and $\mathrm{D}$ & $\begin{array}{l}\text { ORR: } 38 \% \text {; I median PFS: } \\
3.9 \text { months; median OS: } \\
6.3 \text { months; I-year survival } \\
\text { rate: } 63 \%\end{array}$ & $\begin{array}{l}\text { Active, not } \\
\text { recruiting }\end{array}$ & 38 \\
\hline NCT0I478048 & 2 & I 52 patients with RRMM & $\mathrm{E}(10 \mathrm{mg} / \mathrm{kg})$ plus $B$ and $\mathrm{D}$ & $\begin{array}{l}\text { ORR: 66\%; I-year PFS } \\
\text { rate:39\%; 2-year PFS rate } \\
\text { I8\%; median PFS: } 9.7 \\
\text { months } \\
\text { ORR: 63\%; I-year PFS } \\
\text { rate:33\%; 2-year PFS rate } \\
\text { II\%; median PFS: } 6.9 \\
\text { months }\end{array}$ & $\begin{array}{l}\text { Active, not } \\
\text { recruiting }\end{array}$ & 41 \\
\hline $\begin{array}{l}\text { NCTOI } 335399 \\
\text { (ELOQUENT-I) }\end{array}$ & 3 & $\begin{array}{l}\text { estimated enrolment of } \\
750 \text { patients with newly } \\
\text { diagnosed MM }\end{array}$ & $\begin{array}{l}E(10 \text { and } 20 \mathrm{mg} / \mathrm{kg}) \text { plus } \mathrm{L} \\
\text { and } \mathrm{D}\end{array}$ & & $\begin{array}{l}\text { Active, not } \\
\text { recruiting }\end{array}$ & \\
\hline \multirow[t]{2}{*}{$\begin{array}{l}\text { NCTOI } 239797 \\
\text { (ELOQUENT-2) }\end{array}$} & 3 & 646 patients with RRMM & $\mathrm{E}(10 \mathrm{mg} / \mathrm{kg})$ plus $\mathrm{L}$ and $\mathrm{D}$ & $\begin{array}{l}\text { ORR: 79\%; I-year PFS rate: } \\
\text { 68\%; 2-year PFS rate: } 41 \% \text {; } \\
\text { median PFS: } 19.4 \text { months }\end{array}$ & $\begin{array}{l}\text { Active, not } \\
\text { recruiting }\end{array}$ & 37 \\
\hline & & & $L$ and $D$ & $\begin{array}{l}\text { ORR: } 66 \% \text {; I-year PFS rate: } \\
\text { 57\%; 2-year PFS rate: } 29 \% \text {; } \\
\text { median PFS: } 14.9 \text { months }\end{array}$ & & \\
\hline
\end{tabular}

Abbreviations: B, bortezomib; D, low dose dexamethasone; E, elotuzumab; L, lenalidomide; MM, multiple myeloma; NCT, clinical trial registry; ORR, objective response rate; OS, overall survival; P, pomalidomide; PFS, progression-free survival; RRMM, relapsed or refractory multiple myeloma; SLAMF7, signaling lymphocytic activation molecule F7. 
ear pharmacokinetics (area under the curve [AUC]) increased more than proportionally. The systemic clearance (CL) decreased and terminal phase half-life $(\mathrm{T} 1 / 2 \lambda)$ increased with increasing doses, indicating a saturation of target-mediated elimination. Saturation of CS1 receptor by elotuzumab on bone marrow plasma cells achieved $80 \%$ and $95 \%$ at doses of 10 and $20 \mathrm{mg} / \mathrm{kg}$, respectively, without dose-limiting toxicity (DLT). Bortezomib addition did not affect CS1 receptor saturation. No clinically significant differences were found in the pharmacokinetics of elotuzumab based on age (37-88 years), gender, race, baseline lactate dehydrogenase, renal impairment, end-stage renal disease and mild hepatic impairment (the mean terminal half-life is 33 days). ${ }^{34,36}$

\section{Safety and tolerability}

In Phase 1 study, the MTD of IV elotuzumab in combination with oral lenalidomide and dexamethasone is identified, 28 patients were enrolled. Three doses of elotuzumab were given, three patients each for 5 and $10 \mathrm{mg} / \mathrm{kg}$ and 22 patients for $20 \mathrm{mg} / \mathrm{kg}$. There was no DLT at 5,10 and $20 \mathrm{mg} / \mathrm{kg}$ of elotuzumab in first cycle. Elotuzumab in combination with lenalidomide and low-dose dexamethasone was, generally, well tolerated. Based on the efficacy data, $10 \mathrm{mg} / \mathrm{kg}$ of elotuzumab by IV infusion is recommended to combine with lenalidomide and low-dose dexamethasone. ${ }^{34}$

In Phase 3 ELOQUENT-2 trail, patients were randomly assigned to receive elotuzumab plus lenalidomide/dexamethasone (elotuzumab group), or lenalidomide/dexamethasone alone (control group). The median duration of treatment was 17 and 12 months in the elotuzumab and control groups, respectively. Serious adverse reactions were reported in 65\% of the elotuzumab group and $57 \%$ in the control group. The most common grade 3 or 4 hematological AEs included lymphocytopenia in $77 \%$ versus $49 \%$ and neutropenia in $34 \%$ versus $44 \%$, in the elotuzumab and control groups, respectively. The treatment-related AEs in the elotuzumab arm versus the control arm were fatigue (47\% vs $39 \%$ ), pyrexia (37\% vs $25 \%$ ), peripheral edema ( $26 \%$ vs $22 \%$ ), nasopharyngitis (25\% vs 19\%), diarrhea (47\% vs $36 \%$ ), constipation ( $36 \%$ vs $27 \%$ ), musculoskeletal or connectivetissue disorders included muscle spasms (30\% vs 26\%), back pain (28\% vs $28 \%$ ); the other disorders included cough $(31 \%$ vs $18 \%$ ) and insomnia ( $23 \%$ vs $26 \%) .{ }^{38}$

\section{Future directions and conclusion}

Although MM remains incurable, treatment options have improved for patients during the past decade. Myeloma is a genetically diverse disease and thus has provided chal- lenges for the implementation of precision medicine and targeted therapy. A better understanding of biomarkers that predict response to specific therapeutic regimens is needed to improve patient care. ${ }^{42}$ Utilization of CS markers specific for plasma cells has gained interest for directing the treatment of MM since additional targets and therapeutic antibodies are emerging. For example, daratumumab binds to CD38 which is highly expressed on MM cells and was recently approved for patients with MM. CD38 is less abundant on normal lymphoid and myeloid cells. Daratumumab exerts anti-myeloma activity by multiple immune-mediated mechanisms including complement-dependent cytotoxicity, ADCC and apoptosis induction. ${ }^{43,44}$ It is feasible that combined targeting of CD38 and SLAMF7 may improve anti-myeloma activity as downregulation of both receptors may represent a rare event and thus decreased probability of escape from ADCC.

The combination of elotuzumab with other $\mathrm{mABs}$ treatment is also being clinically evaluated. The PD-1 immune checkpoint inhibitor nivolumab, has antitumor immune response in various tumors and approval by the FDA for nonsmall cell lung cancer, melanoma, head/neck cancer, Hodgkin's lymphoma and renal cell carcinoma. In a Phase III multicenter trial, patients with RRMM are randomly assigned to evaluate the clinical benefit and safety for the combination therapy of N-Pd group (nivolumab, pomalidomide and dexamethasone, the investigational arm), Pd group (pomalidomide and dexamethasone, the control arm) and NE-Pd group (elotuzumab, nivolumab, pomalidomide and dexamethasone, the experimental arm). This study is, currently, recruiting participants. (ClinicalTrials.gov Identifier: NCT02726581).

In summary, elotuzumab has shown promising early clinical results and understanding how to best combine targeting SLAMF7 in combination with other immune strategies as well as standard of care agents may lead to improved patient outcomes for the treatment of MM.

\section{Acknowledgment}

This work was supported by National Institute Health (award number: 1RO1CA159727-01_LAH) and National Institute General Medicine (award number: U54GM104942).

\section{Disclosure}

The authors report no conflicts of interest in this work.

\section{References}

1. Fairfield H, Falank C, Avery L, Reagan MR. Multiple myeloma in the marrow: pathogenesis and treatments. Ann N Y Acad Sci. 2016;1364(1):32-51.

2. Morgan GJ, Walker BA, Davies FE. The genetic architecture of multiple myeloma. Nat Rev Cancer. 2012;12(5)335-348. 
3. Jemal A, Siegel R, Ward E, Hao Y, Xu J, Thun MJ. Cancer statistics, 2009. CA Cancer J Clin. 2009;59(4):225-249.

4. Shah N, Callander N, Ganguly S, et al. Hematopoietic stem cell transplantation for multiple myeloma: guidelines from the American Society for Blood and Marrow Transplantation. Biol Blood Marrow Transplant. 2015;21(7):1155-1166.

5. Anreddy N, Hazlehurst LA. Targeting intrinsic and extrinsic vulnerabilities for the treatment of multiple myeloma. JCell Biochem. 2017;118(1): $15-25$.

6. Bianchi G, Munshi NC. Pathogenesis beyond the cancer clone(s) in multiple myeloma. Blood. 2015;125(20):3049-3058.

7. Kumar SK, Lee JH, Lahuerta JJ, et al. Risk of progression and survival in multiple myeloma relapsing after therapy with IMiDs and bortezomib: a multicenter international myeloma working group study. Leukemia. 2012;26(1):149-157.

8. Laubach JP, Moreau P, San-Miguel JF, Richardson PG. Panobinostat for the treatment of multiple myeloma. Clin Cancer Res. 2015;21(21): 4767-4773.

9. Scott AM, Wolchok JD, Old LJ. Antibody therapy of cancer. Nat Rev Cancer. 2012;12(4):278-287.

10. de Weers M, Tai YT, van der Veer MS, et al. Daratumumab, a novel therapeutic human CD38 monoclonal antibody, induces killing of multiple myeloma and other hematological tumors. J Immunol. 2011;186(3):1840-1848.

11. Richardson PG, Moreau P, Laubach JP, Maglio ME, Lonial S, SanMiguel J. Deacetylase inhibitors as a novel modality in the treatment of multiple myeloma. Pharmacol Res. 2016;117:185-191.

12. Arora A, Scholar EM. Role of tyrosine kinase inhibitors in cancer therapy. J Pharmacol Exp Ther. 2005;315(3):971-979.

13. Zhang L, Fok JH, Davies FE. Heat shock proteins in multiple myeloma. Oncotarget. 2014;5(5):1132-1148.

14. Moreau P, Richardson PG, Cavo M, et al. Proteasome inhibitors in multiple myeloma: 10 years later. Blood. 2012;120(5):947-959.

15. Bianchi G, Richardson PG, Anderson KC. Promising therapies in multiple myeloma. Blood. 2015;26(3):300-310.

16. Hsi ED, Steinle R, Balasa B, et al. CS1, a potential new therapeutic antibody target for the treatment of multiple myeloma. Clin Cancer Res. 2008;14(9):2775-2784.

17. Hazlehurst LA, Argilagos RF, Emmons M, et al. Cell adhesion to fibronectin (CAM-DR) influences acquired mitoxantrone resistance in U937 cells. Cancer Res. 2006;66(4):2338-2345.

18. Hazlehurst LA, Dalton WS. Mechanisms associated with cell adhesion mediated drug resistance (CAM-DR) in hematopoietic malignancies. Cancer Metastasis Rev. 2001;20(1-2):43-50.

19. Hazlehurst LA, Damiano JS, Buyuksal I, Pledger WJ, Dalton WS. Adhesion to fibronectin via betal integrins regulates p27kip1 levels and contributes to cell adhesion mediated drug resistance (CAM-DR). Oncogene. 2000;19(38):4319-4327.

20. Bouchon A, Cella M, Grierson HL, Cohen JI, Colonna M. Activation of NK cell-mediated cytotoxicity by a SAP-independent receptor of the CD2 family. J Immunol. 2001;167(10):5517-5521.

21. Tai YT, Dillon M, Song W, et al. Anti-CS1 humanized monoclonal antibody HuLuc63 inhibits myeloma cell adhesion and induces antibody-dependent cellular cytotoxicity in the bone marrow milieu. Blood. 2008;112(4):1329-1337.

22. Palumbo A, Sonneveld P. Preclinical and clinical evaluation of elotuzumab, a SLAMF7-targeted humanized monoclonal antibody in development for multiple myeloma. Expert Rev Hematol. 2015;8(4):481-491.

23. Palumbo A, Cavallo F. Lenalidomide in the treatment of plasma cell dyscrasia: state of the art and perspectives. Haematologica. 2013;98(5): 660-661.

24. Lentzsch S, O'Sullivan A, Kennedy RC, et al. Combination of bendamustine, lenalidomide, and dexamethasone (BLD) in patients with relapsed or refractory multiple myeloma is feasible and highly effective: results of phase 1/2 open-label, dose escalation study. Blood. 2012;119(20):4608-4613.
25. Wang M, Dimopoulos MA, Chen C, et al. Lenalidomide plus dexamethasone is more effective than dexamethasone alone in patients with relapsed or refractory multiple myeloma regardless of prior thalidomide exposure. Blood. 2008;112(12):4445-4451.

26. Gandhi AK, Kang J, Capone L, et al. Dexamethasone synergizes with lenalidomide to inhibit multiple myeloma tumor growth, but reduces lenalidomide-induced immunomodulation of $\mathrm{T}$ and $\mathrm{NK}$ cell function. Curr Cancer Drug Targets. 2010;10(2):155-167.

27. De Luisi A, Ferrucci A, Coluccia AM, et al. Lenalidomide restrains motility and overangiogenic potential of bone marrow endothelial cells in patients with active multiple myeloma. Clin Cancer Res. 2011;17(7): 1935-1946.

28. Gross CC, Brzostowski JA, Liu D, Long EO. Tethering of intercellular adhesion molecule on target cells is required for LFA-1-dependent NK cell adhesion and granule polarization. J Immunol. 2010;185(5): 2918-2926.

29. Barber DF, Faure M, Long EO. LFA-1 contributes an early signal for NK cell cytotoxicity. J Immunol. 2004;173(6):3653-3659.

30. Balasa B, Yun R, Belmar NA, et al. Elotuzumab enhances natural killer cell activation and myeloma cell killing through interleukin- 2 and TNF- $\alpha$ pathways. Cancer Immunol Immunother. 2015;64(1):61-73.

31. Chen D, Frezza M, Schmitt S, Kanwar J, Dou QP. Bortezomib as the first proteasome inhibitor anticancer drug: current status and future perspectives. Curr Cancer Drug Targets. 2011;(3):239-253.

32. Shi J, Tricot GJ, Garg TK, et al. Bortezomib down-regulates the cellsurface expression of HLA class I and enhances natural killer cellmediated lysis of myeloma. Blood. 2008;111(3):1309-1317.

33. van Rhee F, Szmania SM, Dillon M, et al. Combinatorial efficacy of anti-CS1 monoclonal antibody elotuzumab (HuLuc63) and bortezomib against multiple myeloma. Mol Cancer Ther. 2009;8(9):2616-2624.

34. Zonder JA, Mohrbacher AF, Singhal S, et al. A phase 1, multicenter, open-label, dose escalation study of elotuzumab in patients with advanced multiple myeloma. Blood. 2012;120(3):552-559.

35. Lonial S, Vij R, Harousseau JL, et al. Elotuzumab in combination with lenalidomide and low-dose dexamethasone in relapsed or refractory multiple myeloma. J Clin Oncol. 2012;30(16):1953-1959.

36. Jakubowiak AJ, Benson DM, Bensinger W, et al. Phase I trial of anti-CS1 monoclonal antibody elotuzumab in combination with bortezomib in the treatment of relapsed/refractory multiple myeloma. J Clin Oncol. 2012;30(16):1960-1965.

37.Richardson PG, Jagannath S, Moreau P, et al. Elotuzumab in combination with lenalidomide and dexamethasone in patients with relapsed multiplemyeloma: final phase 2 results from the randomised, open-label, phase 1b-2 dose-escalation study. Lancet Hamatol. 2015;2(12)e516-e527.

38. Lonial S, Dimopoulos M, Palumbo A, et al. Elotuzumab therapy for relapsed or refractory multiple myeloma. $N$ Engl J Med. 2015;373(7): 621-631.

39. Dimopoulos MA, Lonial S, White D, et al. Eloquent-2 update: a phase 3, randomized, open-label study of elotuzumab in combination with lenalidomide/dexamethasone in patients with relapsed/refractory multiple myeloma-3-year safety and efficacy follow-up. Blood. 2015;126(23):28.

40. Mateos MV, Granell M, Oriol A, et al. Elotuzumab in combination with thalidomide and low-dose dexamethasone: a phase 2 single-arm safety study in patients with relapsed/refractory multiple myeloma. $\mathrm{Br}$ J Haematol. 2016;175(3):448-456.

41. Jakubowiak A, Offidani M, Pégourie B, et al. Randomized phase 2 study: elotuzumab plus bortezomib/dexamethasone vs bortezomib/dexamethasone for relapsed/refractory MM. Blood. 2016;127(23):2833-2840.

42. Wang Y, Sanchez L, Siegel DS, Wang ML. Elotuzumab for the treatment of multiple myeloma. J Hematol Oncol. 2016;9(1):55.

43. Costello C. An update on the role of daratumumab in the treatment of multiple myeloma. Ther Adv Hematol. 2017;8(1):28-37.

44. Usmani SZ, Weiss BM, Plesner T, et al. Clinical efficacy of daratumumab monotherapy in patients with heavily pretreated relapsed or refractory multiple myeloma. Blood. 2016;128(1):37-44. 


\section{Publish your work in this journal}

Cancer Management and Research is an international, peer-reviewed open access journal focusing on cancer research and the optimal use of preventative and integrated treatment interventions to achieve improved outcomes, enhanced survival and quality of life for the cancer patient. The manuscript management system is completely online and includes a very quick and fair peer-review system, which is all easy to use. Visit http://www.dovepress.com/testimonials.php to read real quotes from published authors.

Submit your manuscript here: https://www.dovepress.com/cancer-management-and-research-journal 